\title{
Using the Analytical Hierarchy Process Framework to Study Bank Selection Criteria of Students in Institute of Professional Studies in Ghana
}

\author{
Abednego Feehi Okoe ${ }^{1}$, Aihie Osarenkhoe ${ }^{2} \&$ Robert E. Hinson ${ }^{3}$ \\ ${ }^{1}$ University of Professional Studies, Legon, Accra, Ghana \\ ${ }^{2}$ Department of Business studies, Faculty of Education and Economics, University of Gävle, Sweden \\ ${ }^{3}$ Business School, University of Ghana, Legon, Accra, Ghana \\ Correspondence: Aihie Osarenkhoe, Department of Business studies, Faculty of Education and Economics, University \\ of Gävle, Sweden. E-mail: aoh@hig.se
}

Received: May 20, 2013

Accepted: June 20, 2013

Online Published: August 1, 2013

doi:10.5430/jms.v4n3p27

URL: http://dx.doi.org/10.5430/jms.v4n3p27

\begin{abstract}
The purpose of this study is to investigate bank selection criteria among students at the Institute of Professional Studies, Ghana. Extant literature has employed mainly quantitative approach. In order to contribute to existing knowledge, qualitative research design was adopted using the Analytical Hierarchy Process which demands that the decision problem is structured into a three level hierarchy, thus ensuring in-depth appreciation of the factors determining bank selection. The findings indicate that undergraduates in IPS place high emphasis on the convenience, customer service, and speed dimensions of bank services. Studies focusing on undergraduates' bank selection in developing countries context are limited. This study will make important contribution in helping bridge the gap but more importantly provide information on the importance of the selection criteria.
\end{abstract}

Keywords: banks, decision making, analytical hierarchy process, IPS, Ghana

\section{Introduction}

The services sector is increasingly playing a pivotal role in the global economy and the growth and development of countries. Trade in services demonstrated relative resilience in the latest financial and economic crises in terms of lower magnitude of decline, less synchronicity across countries and earlier recovery from the crises. Such resilience has led many countries to incorporate services trade into their post-crisis national trade and growth strategies (World Bank, 2012). Thus the importance of banking and financial services in the world services industry cannot be overemphasized (Mishkin, 2001). New technologies and information systems forced these institutions to offer more sophisticated and technological services in the banking and finance industry (Katircioglu et al 2012). Today`s competitive financial atmosphere also led banks and financial institutions to improve their service quality and follow new technologies.

Furthermore, globalization has brought in its wake many changes in the economic and business environment worldwide. Ghana is not exempt from these changes and virtually all industries including the banking sector are being affected by this trend. Blankson et al (2009), report that, the global banking industry has been characterized by increasing competition since the early 1980s. They attribute this occurrence to a number of interrelated factors such as competition and deregulation that have revolutionized the distribution of many financial services. The Ghanaian banking sector has seen tremendous transformation in the last decade (2000-2010). This transformation has largely manifested in the increase in the number of banks between these periods. In the last ten years, the size of Ghana's banking industry and as such the number of banks has grown significantly to up twenty-seven (27) (www.bog.gov.gh). This has whipped up competition among the banks and several of them are striving to adopt various customer attraction programmes to improve their competitiveness.

Studies on bank marketing are not new as a wide variety of marketing constructs related to retail customers have been investigated; including key motivations (Hinson et al, 2009), bank loyalty (Beerli et al, 2004), bank selection (Thwaites and Vere, 1995; Huu and Karr, 2000), bank service quality (Hinson et al, 2009), and multiple bank users (Mokhlis et al, 2009). One marketing construct related to retail customers that has attracted a plethora of studies has been the patronization process of retail customers or the reasons on the basis of which customers choose to bank with specific 
commercial banks (Kaynak, 1986; Gupta and Torkzadeh, 1988; Boyd, Leonard and White, 1994; Zinelden, 1996; Gerrard and Cunningham, 2001; Blankson et al, 2007; Hinson et al, 2009).

Following a review of the aforementioned literature, it appears two themes concerning the patronization process of retail customers emerge. First, majority of previous studies related to bank selection decisions appear to have been conducted in industrialized nations such as the USA and Europe (Schlesinger et al 1987; Zineldin, 1996) and to some extent newly industrialized nations such as China, Malaysia and Singapore (Denton and Chan, 1991; Gerrard and Cunningham, 2001; Huu and Karr, 2000). Whilst it is true that the findings of such studies have undoubtedly made a significant contribution to knowledge on bank selection criteria of retail customers, Almossawi (2001) raises an essential issue of the transferability of such findings to what Blankson et al (2007) refer to as liberalised developing countries such as Ghana due to differences in cultural, economic, political and legal environments. Second, whilst a few studies have been directed towards younger age groups, it seems majority of such investigations has focused on the general population as its population of interest. This study therefore is an attempt to bridge this gap by extending the study of bank selection criteria to an examination of undergraduate students in Ghana. The phenomenon of undergraduate student bank selection has been explored to some extent in other cultures including Singapore (Gerrard and Cunningham, 2001; Huu and Karr, 2000), Bahrain (Almossawi, 2001), Malaysia (Mokhlis et al, 2009). Mokhlis et al, highlighted three reasons why banks in Malaysia must pay close attention to the undergraduate student segment. These are summarized as follows: In terms of buying power, the student market is expanding and has become lucrative; Students need a bank account to negotiate their educational loans or for parental contribution and may be obliged to administer their own financial affairs for the first time; and There exists a potential for above-average profitability in the future.

These reasons seem applicable to Ghana. Students have become targets of the banks in Ghana because they represent a potentially rewarding segment, medium to long term (Hinson et al, 2009). Whilst Hinson et al. (2009), studied undergraduate students' perception of service quality in Ghana, this study investigates bank selection criteria of undergraduate students in Ghana. Whilst their study no doubt contributed immensely to the scanty knowledge on student segment within developing country and African contexts, bank studies focusing on student bank selection criteria in a developing economy appear to be rarer. This paper explores on a qualitative manner, issues attendant to the ways by which undergraduate students select banks in Ghana.

This study aims to: 1) to generate a pool of statements which undergraduate students employ in their evaluation and selection of banks; 2) to synthesize and reduce these statements into key determining factors explaining undergraduate students' selection of banks; 3) to determine whether and how these factors are prioritized according to their importance; 4) to determine whether or not the undergraduate body is a homogenous group in relation to their method of bank selection.

\section{Literature Review and Conceptual Framework}

Studies on retail bank marketing are not new. Mokhlis et al (2009) report that since the late 1960s, much has been written on retail bank marketing with the majority of the literature relating to banking behaviour of retail customers. Such studies have focused on marketing themes spanning market segmentation, bank loyalty, bank selection decisions, bank image and bank services quality. However, one marketing theme that has attracted considerable scholarly attention has been focused on bank selection criteria by bank customers in different countries. (Mason and Mayer, 1974, Anderson, Cox and Fulcher, 1976; Evans, 1979; Kaynak, 1986; Gupta and TorkZadeh, 1988; Hon and Tom, 1994-95; Boyd, Leonard and White, 1994; Holstius and Kaynak, 1995; Zeneldin, 1996). We review next some key studies that have focused on bank selection criteria in different geographical contexts. Lewis (1982) conducted a study on banking behaviour among British students which revealed that 92 per cent of the 514 first year college students thought they would stay with their present bank until the end of their course while 44 percent believed they would continue with the same bank. About 80 percent of the 202 final year students believed they would continue with the same bank even after graduation. Further, the study revealed that convenience of location to college and parental advice and influence were the predominant factors influencing students' choice of bank.

Schlesinger et al (1987), in a study conducted in New York State found that the three most important factors in selecting a bank for small business customers were lending rates, accessibility of borrowing, and the number of service offered. Price of service was also found to be an important bank selection factor in another survey conducted by Buerger and Ulrich (1986). Laroche et al (1986) conducted a survey in Canada and found that speed of service, and factors relating to the competence and friendliness of bank personnel and convenience of location were the major factors which consumers perceived as important in selecting a bank. Schram (1991) found that "convenience... remains the primary reason why most college students choose their banks". He also noted that family loyalty to banks appears 
to be exhibited among students. A survey of 209 university students by Khazeh and Decker (1992-93) in Maryland, USA to determine customers' bank selection criteria also found that service charge policy, the reputation of the bank, interest charged on loans, time required for loan approval and friendly tellers were considered as the top five determinants of bank selection decisions. Holistius et al (1995 and Razavi et al 2012), cited efficiency and courtesy as the most important attributes in determining overall customer satisfaction, while other important attributes were convenience of location, range of services, reputation and availability of innovations. Similarly, the importance of location decisions in satisfying customers is also emphasized in the previous studies (Kaynak and Kucukemiroglu, 1991).

A study by Thwaites and Vere (1995), also conducted among British students indicated that proximity of an ATM to college, free banking services, and overall students offer were the top three selection criteria employed by college students in selecting which banks to patronise. Another study on bank selection criteria by Yue and Tom (1995) was based on Chinese-Americans residing in Sacremento, California. The important factors of bank selection by the customers were found to be efficiency of services offered, bank's reputation, bank fees, location and interest rates on savings account. Twaites, Brooksbank and Hanson (1997) undertook a research in New Zealand in the area of student banking focusing on factors that influence their selection of banks. They found that fast and efficient service, friendly and helpful staff and reputation of the bank are important factors in the selection of a bank. Some students were found to be sensitive to the core services offered, some were conscious of every aspect of their banks and some others would shop around for the best deal.

In Singapore, Huu and Karr (2000) sampled 198 undergraduates' students to identify factors which influence their bank selection decisions. Using "analytical hierarchy process", they found that undergraduates place high emphasis on the pricing and product decisions of bank services. The third party influences were found to be the least important selection criteria. A study by Poh in (Gerard and Cunningham, 2001) also conducted in a Singapore setting among university and polytechnic students found that factors relating to ATMs and speed of service were the most important criteria affecting their bank selection. Criteria relating to third party influences were found to be so important during the pilot test and therefore were excluded from the actual study. In Singapore, Gerard and Cunningham (2001), again conducted a research in the area of student banking sampling 184 undergraduates to establish a ranking of the various factors which influence their banking selection dimensions. Employing factor analysis, seven bank selection dimensions were identified by the researchers, the most important being undergraduates should "feel secure", followed by "electronic services" and "service provision". Consistent with the findings of Huu and Karr (2000), the "third party influences" was found to be the least important dimension rated by undergraduates.

In Bahrain, Almossawi (2001) conducted a research which examined the bank selection criteria employed by college students. His study revealed that the key factors determining college students' bank selection were: bank's reputation, availability of parking space near the bank, friendliness of bank personnel and availability and location of automated teller machines (ATM).Pass (2006) surveyed the opinions of 373 students from four community colleges and universities located in a large metropolitan area of the Western United States to obtain information about the reasons for students switching banks and selecting new banks. Pricing and convenience were found to be the principal reasons for selecting a new bank and 'hypothetically' switching banks. In a recent study conducted in Malaysia, Mokhlis et al (2009) found that undergraduate students place more emphasis on secure feelings, ATM service and financial benefits when choosing a bank to patronise. The findings also showed that undergraduate students are not a homogenous group in regard to the bank selection process. More recently, Hinson et al (2009) surveyed 2000 customers of 22 banks in Ghana. The study revealed that overall bank customers view proximity or accessibility as the most important factor in selecting a bank.

Extant literatures show that there are several determinants of the bank selection process. Most of these studies have been conducted in the more developed countries (Denton and Chan, 1991) and to some extent newly industrialized nations such as Taiwan, Singapore and Malaysia. Such studies no doubt have contributed substantially to the literature on bank selection but their findings may not be applicable to developing countries like Ghana due to different cultural, political and economic setup. Blankson et al (2007) did some work on undergraduate bank selection which partly covered Ghana. Hinson et al (2009) surveyed the opinion of 2000 retail customers of 22 banks in Ghana to determine their bank selection criteria. Hinson et al. (2009) in a study of banks operating in Ghana found out that training of bank staff is critical to the successful delivery of services. They however cautioned that banks operating in a developing country context must consider the influence of culture on customers so as to help provide effective service. Buchs and Mathiesen (2008) in a study on "banking competition and efficiency in Ghana" noted that in spite of the high overhead costs, Ghanaian banks' pre-tax returns on assets and equity are among the highest in Sub-Sahara African suggesting that in spite of the challenges, patronage is still high. It however, appears that current literature on banking in Ghana lacks studies on bank selection criteria among undergraduate students and this study aims to bridge this gap. 


\subsection{Consumer Behavior in the Financial Services Industry}

Within the traditional structure of the financial services industry consumers in the past had little choice in terms of selecting financial instruments and delivering channels (Cook, 2002). The rigid structure of the industry combined with the operation of cartels, meant that consumers had to accept the form and price of both financial instruments and delivery channels (Beckett et al, 2000). Consumers were locked into buying patterns and had little incentive to change. A number of interrelated factors such as competition and deregulation (Blankson et al, 2007), and new forms of technology (Beckett et al, 2000) have revolutionalized the distribution of many financial services. These changes have had a significant impact upon consumer behaviour. According to Beckett et al. (2000), consumers are now more disposed to change their buying behaviour when purchasing products. Consequently, bank service providers are less certain that their customers level of loyalty.

Understanding and adapting to customer motivation, attitudes and their ultimate selection decisions for offerings such as banks are not an option but an absolute necessity (Kotler, 2000). This is consistent with the work of (Weber, 1949) in which he argued that it is necessary to identify the underlying constructs which determine consumer behaviour. To this end, factors impinging on consumers' selection of banks are an important research task (Devlin, 2002). Majority of such investigations seem to have focused on the general population as its population of interest though some studies have been directed towards younger age groups. The viability of this group is derived from the fact that though majority of undergraduate students are unemployed and rely primarily on students' loans and family support, they provide an excellent business support for bank (Mokhlis et al 2009). First, the student market has seen a tremendous expansion and has become very profitable. According to Thwaites and Vere (1995), despite their relatively basic banking needs, students are to some degree a captive audience and at the stage in the purchase cycle where they may be more responsive to marketing activities from financial institutions. Third, students market is perceived to have the potential for above-average profitability, medium to long term. Thwaites and Vere (1995) concluded that the ability to develop a presence in the student market through appropriate acquisition and retention strategies is therefore likely to have an influence on bank's future market share and profitability. Presented below is a framework of bank selection decision criteria by undergraduates adapted from Huu and Kar (2000).

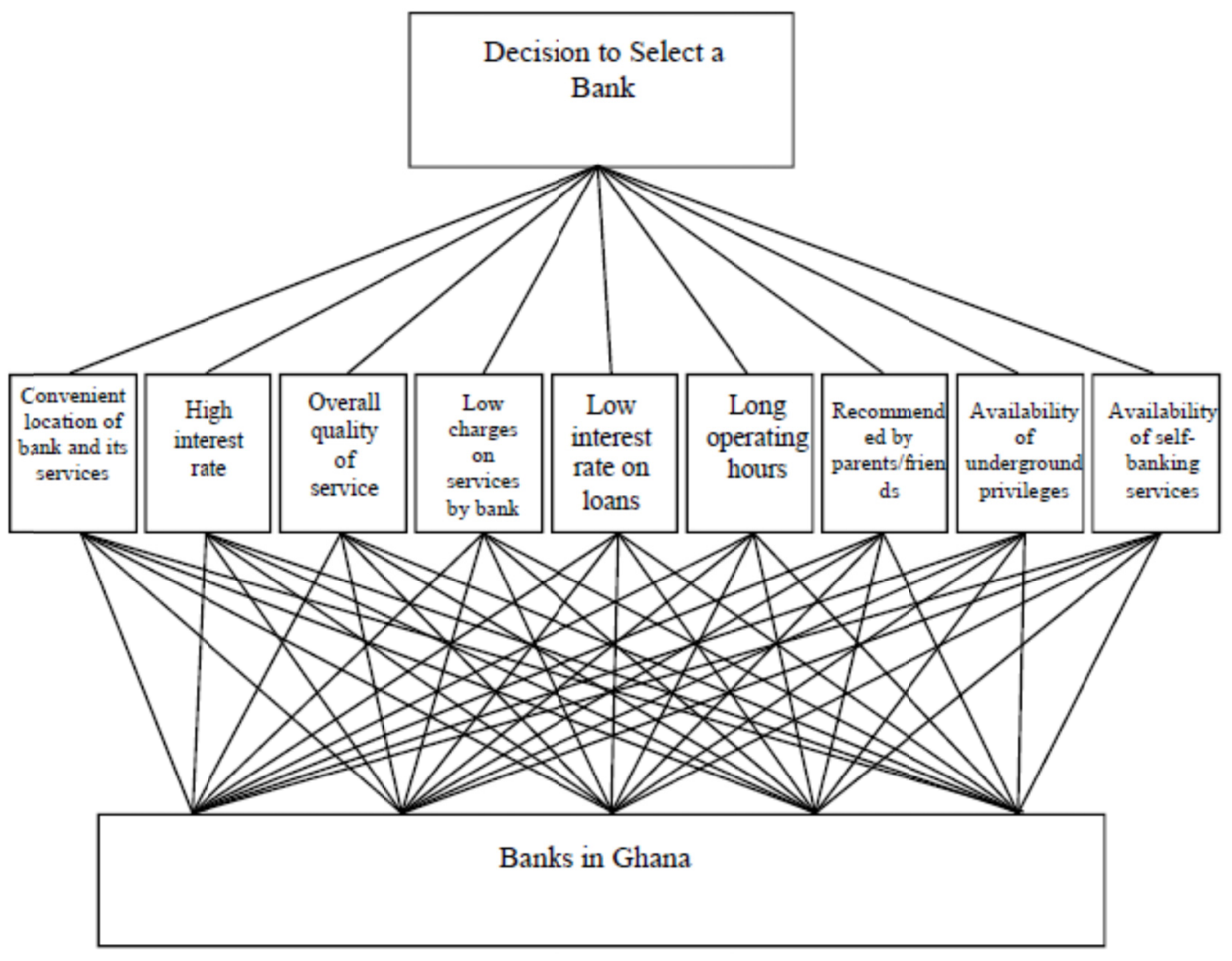

Figure 1. Framework for bank selection

Source: Adapted from Huu and Kar (2000) 
This study examines the predominant factors that have a bearing on undergraduates' bank selection decisions by adopting Huu and kars' (2000) Analytic Hierarchy Process (AHP) (see figure 1). The AHP is a multi-objective, multi-criteria theory of measurement. It addresses the issue of how to structure a complex decision problem, identify its criteria (tangible and intangible), measure the interaction among them and finally synthesize all the information to arrive at priorities which depict preferences. Although the utility of the AHP for methodology has been demonstrated in studies conducted in several parts of the world, it appears not to have been researched upon in Ghana. This study wishes to highlight the usefulness of the AHP methodology in bank marketing in Ghana. Following Huu and Kar, (2000), the decision problem for this study was structured into three-level hierarchy. The top-most level of the hierarchy is the macro decision to select a bank. The middle level contains the selection attributes and the final level represents the bank s in Ghana.

\section{Research Methodology}

To fulfil the purpose of this study, a case study approach is adopted. Whilst some researchers have criticized the case study approach on the basis that it does not allow for transferability of findings, this approach is employed in this study in view of its qualitative exploratory nature and therefore an in-depth knowledge is required. Case study approach (Yin, 2003 ) is more appropriate. We follow the examples of Spears et al (2001), Cunningham et al (2006) and Blankson et al (2007) in adopting the student cohort as the empirical context for this study. Whilst others have argued that students cannot be considered as cohorts, Thwaites and Vere (1995) have pointed out the special features and importance of the undergraduate market in the eyes of bankers because of their potential. Although there has been criticism regarding the use of students as surrogate consumers and also about the validity and generalizability of student samples, university students are deemed appropriate for this study since students are actual customers of banks and conversant with bank products (Yoo et al, 2000). Blankson et al (2007) posited that although students differ from non-student adults, they do represent homogenous groups even across cultures.

We adopt Huu and Kar's (2000) Analytical Hierarchy Process methodology where a decision process is decomposed into a hierarchy. The AHP is described as a multi-objective, multi-criteria theory of measurement which focuses on the issue of structuring a complex decision problem, determining its criteria (quantifiable or intangible), measuring the interaction among them and synthesizing all these information in arriving at priorities which connote preferences (Huu and Karr, 2000). The AHP can provide assistance to bank managers in obtaining an in-depth appreciation of the criteria that undergraduate students consider vital in their selection of banks as well as the weight of their preferences. Other techniques for multi-criteria decisions making include the multi-attribute value theory (MAUT) and the multi-attribute utility theory (MAUT). Whilst these techniques could serve as alternative methodologies to AHP, Lai and Hopkins (1995) found that MAUT is similar to AHP in effectiveness.

The AHP methodology has largely been employer successfully in studies across the world but not much researched upon in Ghana. This study highlights the importance of the AHP methodology in bank marketing in Ghana by adapting the technique to a qualitative study.

Decomposing a consumer choice problem (bank selection) involves the structuring of a hierarchy in terms of the overall objective (decision to select a bank), the selection criteria and the decision alternatives (banks). The first step in the research design is to identify the criteria that undergraduates consider important when selecting a bank. A review of the literature on bank selection decisions of consumers was undertaken. The extant literature generated an extensive list of criteria with the most important ones cited as services, location, operating loans, bank charges and convenience.

To identify the relevant criteria of undergraduate's bank selection decision in Ghana; a focus group discussion was conducted at the Institute of Professional Studies (IPS) in Ghana. A convenience sample of 12 undergraduate students which include 2 students from each level was selected for participation in the focus group discussion. The focus group was divided into two groups of six each and separate discussions held with them. However, on the day of the discussion, two students were absent thus reducing the sample size to ten (10). The criteria for selection considered gender to help throw light on whether or not the undergraduate student body is a homogenous group in relation to their method of bank selection. It also considered selection of participants from first to final year students. This helped determine the factors that influence various categories of undergraduate students. Participants were encouraged to talk freely list the words, descriptions, statements and their reasons for selecting, staying with, or recommending their own banks (Dickinson and Wilby, 1997). Analysis of the focus group sessions was done via inductive reasoning to help identify statements that influence participants' bank selection and which will help incorporate into a survey for future studies.

\section{Results}

In order to understand the prioritisation of the criteria that undergraduate students in IPS deem important in bank selection decisions, focus group discussions were held with ten participants. Findings from the focus group discussions 
are presented and discussed below. The discussion is undertaken in the light of the framework adopted from Huu and Karr (2000) Decision Hierarchy model. Our guiding propositions are on three levels: 1) Bank selection decisions; 2) Bank selection criteria; and 3) Banks in Ghana.

\subsection{Bank Selection Decisions}

Bank selection decision deals with participants' reasons to bank rather than save at home. Issues that fall under bank selection decisions include participants' general view of banks in Ghana, what they think about their services, the reasons for choosing to bank and how long they have been banking.

On the issue of the participants' general view of banks in Ghana, here are some responses:

Harriet (H): I think they are doing well. The Nigerian banks have brought in a lot of competition.

Kingsley (K): Banks have improved generally. Oswaldo (Os): Concerning conditions they have improved but are not serving the main purpose of giving loans. Faustina (F):I think they have improved.Selorm (Se):My observation is that competition has made them better. Linda (Li): first, they were not doing well. Now they are ok.Salifu (As): They have improved.Matilda (Ma): Banks in Ghana...well I don't know, what I think or what I have seen is that for example if you want to invest. May be you need to access their fixed deposit, you need to have a large sum of money before you can do that and they are encouraging us to save and invest but I think they have improved because we have a lot of banks now.Abdulai (Ab): yeah for the banking industry they have improved ... yeah. Fred (Fr): In the major cities, I will say there have been greater improvements because the numbers of banks in the cities have increased. Unlike in the rural areas where there are few... so in terms of rural banking they have not.

The general consensus irrespective of geographic variability is that the banking sector in Ghana has seen improvement and this could be attributed largely to increased competition as a result of expansion. On why participants decided to bank, they expressed the following diverse opinions:

Se: There are certain things you need to buy so the bank helps you to plan. That is why I don't like banks close to me. As women, we are meant to do things and it costs. The men count us as one of the projects. We need to buy things on their behalf. That is why I save. K:I bank for prudent management of my funds. Ag: I bank because it is good for me because it allows me to save. To take money from the bank, I have to go through a lot of stress and this serves as a check on me so I don't go to withdraw money often. Os: I like to save. Ha: I am a heavy spender, so the bank serves as a check. With my current bank, I am allowed to withdraw only twice a month so I don't go there often.

Fa: I am a salaried worker that is why I bank.Ab: Well...just to keep monies I don't need right now. May be if it is with you, you will be tempted to use it for unnecessary things. Fr: Well, the same reason as Abdulas' and as a worker, I will need a bank account for my salary, so one of my accounts is for salary and the other for personal savings. Sa: Basically, there are two reasons, one is student loan scheme. You will obviously need a bank account and the other one is that I don't live here and my parents have to send me money through it. Ma: I do because of the interest I will earn on my savings; I can use it for something else and for the student loans that I can access easily.

It appears that the underlying reason for females employing the services of a bank is to avoid overspending while for males; the reason is to save for the future. There are also compelling reasons for bank selection decisions including the need to benefit from the student loan trust or as a prerequisite at the work place. The popular notion that the youth has a poor saving culture appears to be waning. The minimum number of years that participants have been banking is three (3) years and the maximum is eight (8) years. Correspondingly, the younger ones who are in their first or second year in their four year programme fall within the 3 year minimum bracket with the older ones in the final year of their programme falling within the upper limit of eight (8) years category.

\subsection{Bank Selection Criteria}

In order to understand the characteristics that undergraduate students deem important in bank selection decisions, the views of the participants in the focus group discussion were considered. These include reasons for selecting the present bank or changing banks, the most important factors considered in selecting a bank, and whether or not one would consider changing banks after school.

Inquiring about the reasons for choosing a particular bank, participants had this to say: Ag: I was a student at $I P M C$ when my bank came there to give a talk. My friends later convinced me that they have good customer service. Fa: I chose my bank because they are close to me. Moreover, I like their customer service. Os: I chose IBG because of proximity. I really like UT but they are not close to me. They support businesses. Li: As for me, I chose Ecobank because they keep me informed about their services. Se: I usually depend on my company to choose a particular bank. Funny enough, I have personally chosen only one bank and that was because of their presence and allowing me to have 
access to international transactions. My husband lives in the United States. Sa: I bank with Barclays and it's a global bank you know... 'emm'... we the youth of late we want 'flex' banks, banks that have 'swagger' you know... hahaha...I mean the banks that you can brag to your friends that you use. Another thing is the accessibility. I have an ATM card that I can withdraw money with and its even Visa...am ... as a student, accessibility, that is what I expect from a bank. That is for now; I don't care about the interest rate and minimum deposits. Ma: I will also say accessibility. That is the first thing because I am on campus and then the bank is just close to me. I just walk there and do what I have to do... yeah, that is the main thing. Fr: I chose IBG because of their minimum balance which I think is GHф 5 or so. I think it's good for someone who also wants to start saving. They should design the savings account to be like an investment account so that the return you get on your savings will be more. Ab: For me what I want in a bank is a bank that can give me what I want... for instance, if I need a loan, it should not take time. As a student, I need money to do something small.

There are varieties of reasons for choosing a bank depending on individual's peculiar needs. These include: customer service, accessibility (convenience), prompt feedback, company choice, international presence, minimum balance, and bank support.

On the issue of the most important factors respondents consider (in order of priority) in selecting a bank, here are some issues: K: For me, I consider the following: convenience, customer service and the attractiveness of the bank. I want to be treated like a k king. Ha: I consider convenience, customer serviceand flexibility. Li: for me, prompt service and feedback. Sa: Flexibility is key. Ag: I consider bank rate. Customer service is also very important to me. Fa: Convenience and when I need help, I expect them to help. Ma: Good customer service. Ab: The speed... when you go there you don't keep long. I will add accessibility. Fr: Mine is quite funny... the layout, the office... when I enter how spacious the banking hall is. Sa: I will say brand name, accessibility, easy processes. Ma: Me I consider security, accessibility, and speed. Ab: For me, I will consider image of the bank, branch network, and speed. Fr: For me, I will consider customer service first, then the interest rate earned on savings and also the prestige of the bank.

The three most important criteria factor affecting undergraduates' bank selection decisions are convenience, customer service and speed of service. They are followed by image and attractiveness of the bank and high interest rate on savings.

On the question of whether their respective banks are their first, respondents had this to say: H: Because of the (huge minimum) bank balance, I moved to save with ADB but then, again the later was rude. I moved to Ecobank partially because they had a particular service that I wanted. Besides, the bank is close to me. Se: Funny enough, I have a number of accounts, I started with GCB. I left because I felt they were old fashioned. Most of the time however, I changed banks because my company changed banks. Os: I was paid through the bank therefore I had to use the bank that the company used. When I stopped work, I changed the bank to the one very close to me. Fr: I rather added one. Ma: I had one but then I added another one and that is the active one.

Findings show that when students are dissatisfied with a particular bank, they do not necessarily close the account. Rather, they keep the account dormant and open a new account with another bank which they keep more active.

On whether or not they would change banks on completion of their education, here are some sampled opinions: Se: I wouldn't change. I will keep them open and still open more. Fa: I will like to try other banks. Li: No, I will not change. K: I will change when I finish school. Ha: I will change when I start working. Ab: I will not change... may be added up. Fr: I wouldn't change... maybe I will add more. Ma: I'm not sure because they cheated me. May be I will add.

The responses confirm the fact that students would not close their old bank accounts but rather add to it when they become gainfully employed. It also points to the fact that banks should focus more on customer share and not market share that is, how active the account is and not merely keeping an account. It is also pertinent to note that students in the lower levels are more emphatic in their responses that they would not change banks whilst their colleagues in upper levels think otherwise. It is reasonable to conclude that expectations and perceptions of students change in their assessment of banks in Ghana. Banks must therefore continually monitor the expectations and perception variables so as to build a long-term relationship with them.

\subsection{Banks in Ghana}

In conclusion, participants were asked to name the banks they keep accounts with.

Li: Ecobank; As: TTB, Se: Zenith, TTB, Amalbank; F: Intercontinental bank; Os: Intercontinental bank and GCB; H: Ecobank; Fr: $G C B$, Ecobank and Intercontinental bank Ghana (IBG); Sa: Barclays; Ma: IBG; Ab: IBG. With 
reference to the focus group discussions, bank selection criteria of IPS undergraduate students are diagrammatically represented below.

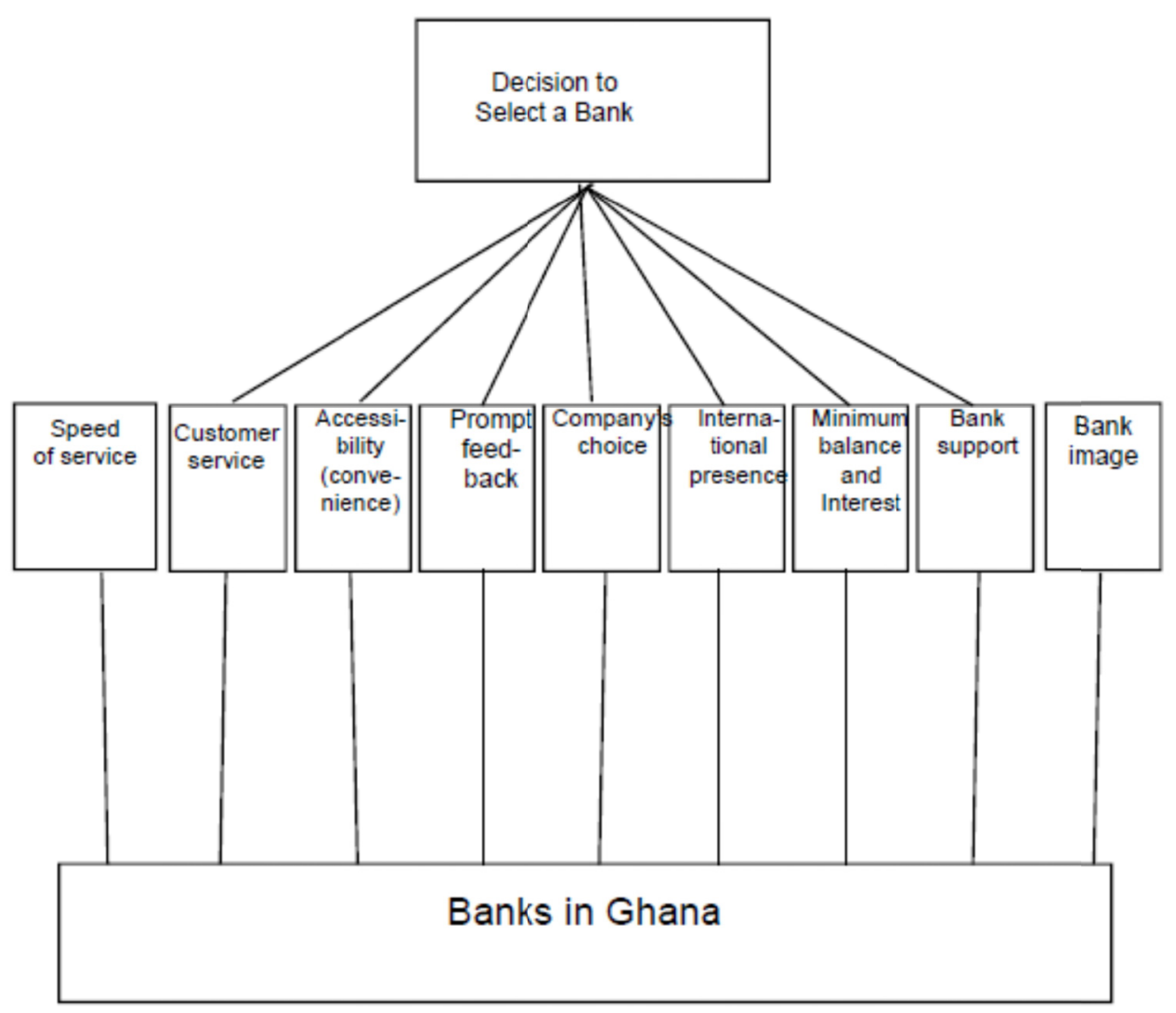

Figure 2. Bank selection decision of IPS students viewed from the perspective of Analytical Hierarchy Process (AHP) framework

Source: Based on findings from focus group discussion

\section{Discussion}

Nine criteria have been identified as reasons for bank selection by IPS undergraduate students. These include: Customer service, speed of service, minimum balance and interest, international presence, company's choice, prompt feedback, bank support, bank image, and convenience. The three most important criteria affecting undergraduate bank selection decisions are convenience, customer service, and speed of service. These factors are largely consistent with findings in other contexts including Almossawi (2001) in Bahrain; Huu and Karr (2000) in Singapore; Khazeh and Deckor (1992-93) in Maryland, USA; Laroche et al. (1986) in Canada, and Lewis (1982) in Britain. It appears therefore that there is a homogenous consumer group as far as undergraduate bank selection decisions are concerned despite the cultural differences. A point of departure surprisingly, is the low influence of parental advice on bank selection decisions in the case of undergraduate students at IPS. This however featured prominently in other studies (Anderson et al., 1976; Huu and Karr, 2000; Almossawi, 2001; Ying and Chua, 1989; Lewis, 1982). It is also important to note that nine out of the twenty-seven banks were named by respondents as their banks. This could be explained perhaps on the basis that the sample size was small. However Ecobank (GH) limited and Intercontinental Bank Ghana Limited (IBG) were the dominant banks in the study. The choice of IBG is not surprising as it is the nearest bank to students on IPS campus. Ecobank is reputed to be a prestigious bank and it has a positive corporate image.

In banking today, the different actors offer a wide variety of products/services. Every bank has to consider how to build and protect its competitive position. They are forced to find a new basis for competition. This observation is in line with that of Zineldin (1996). From the bank customers' point of view, factors relating to functional quality such as friendliness and helpfulness of personnel, accuracy in account transaction management, efficiency in correcting mistakes, and speed of service and decision making clearly emerged as the most important determinants of bank selection. However, in contrast to our findings, Zineldin`s (1996) study shows that functional quality is more important 
than traditional marketing activities. And that convenience of location, price and advertising had a minor effect in a bank selection.

To further determine the managerial implications of these results for bank marketing, the findings were analyzed using Huu and Karr's Analytical Hierarchy Framework (AHP). Based on these findings, we propose an adaption of the framework presented below. The framework (Figure 3) indicates that bank must consider the four levels to attract and nurture their relationships with undergraduate students. At the first level, banks must interrogate reasons for banking by undergraduate to help them integrate those factors into their marketing tools. The second level requires that bank managers incorporate the three most important criteria undergraduates consider in their bank selection decisions namely convenience, customer service and speed into their value proposition and deliver on those promises. The third level focuses on the other six dimensions of bank selection criteria, including prompt feedback, bank support, company's choice, international presence, minimum balance and bank image. Bank managers must use these factors to differentiate their services. The company choice dimension requires that banks employ a relationship marketing approach to nurture their relationship with companies. In so doing, they win over their employees as well. The final level describes the alternative banks available and therefore the respective banks must brand themselves based on the various dimensions identified.

Furthermore, to investigate the managerial implications of these results for bank marketing, it is pertinent to mention that traditionally, product marketing revolves around product, price, place and promotion. Using this framework, the criteria in Level 2 of the decision hierarchy (Figure 3) can be classified into the marketing mix characteristics of the four Ps. The product dimension includes overall quality of service and the availability of self-banking facilities. The price dimension includes high interest rates, low service charges, and low interest rates on loans. The place/delivery dimension includes convenient location and long operating hours. The promotion dimension includes recommendations by parents/friends, and the availability of undergraduate privileges. The nine attributes under the four dimensions and the priorities of level 2 and level 3 denote the marketing mix characteristics of the banks.

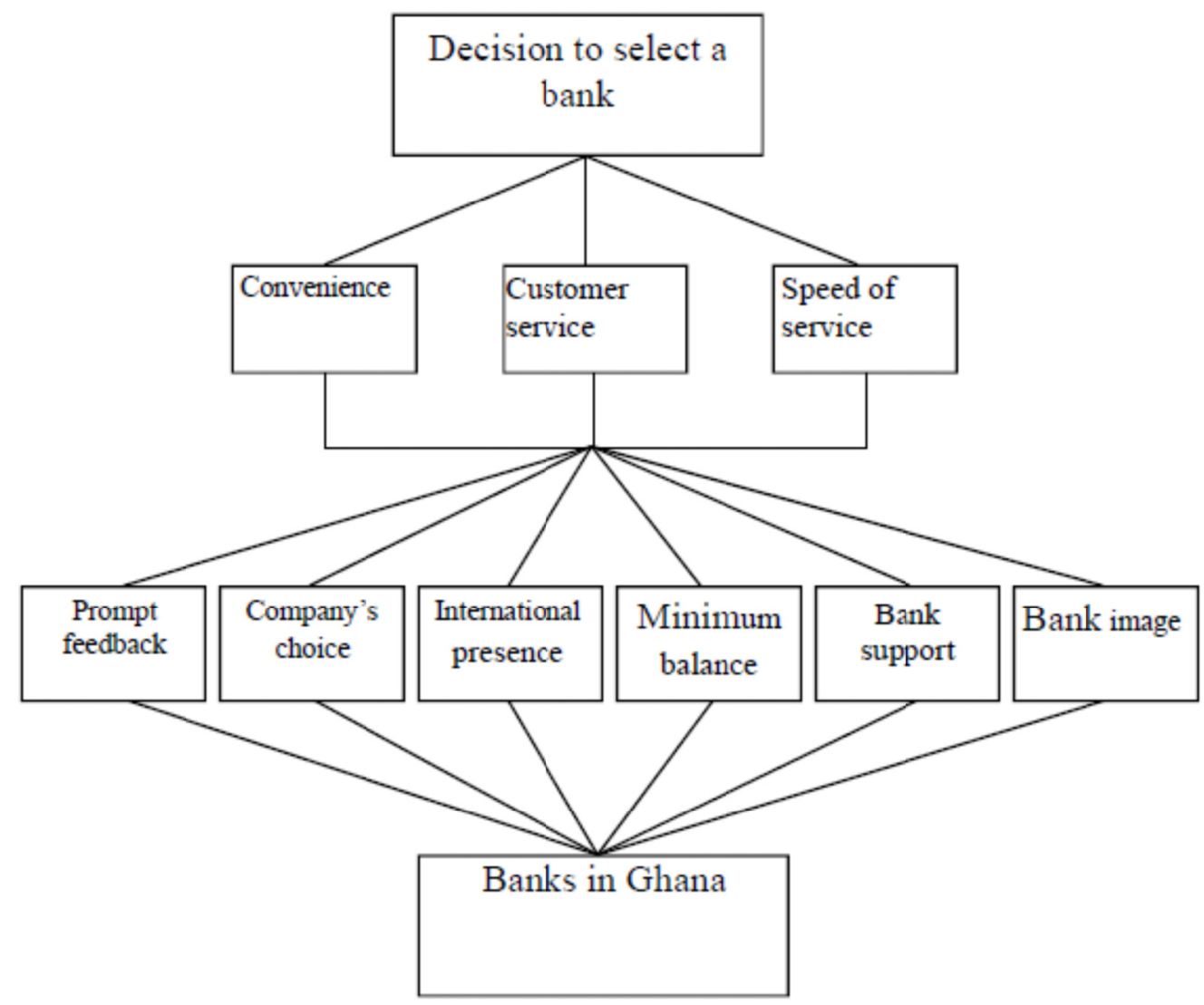

Figure 3. Proposed Analytical Hierarchy Framework for student bank selection in Ghana

Source: Based on findings from focus group discussion 


\section{Concluding Remarks and Implications}

The purpose of this paper is to investigate bank selection criteria among students at the Institute of Professional Studies, Ghana. Considering the above findings, this study contributes to the body of academic knowledge by shedding more light into the choice criteria, which influence customers' bank selection and future relationship with the bank. At the same time, this study has several implications for bank marketers, as it reveals which service attributes are of most importance for customers and determine their decision of cooperating with the bank. An accurate appreciation of choice criteria may aid bank marketers in their attempts to deliver offerings, which will motivate customer choice.

This study will be important with the point of view of academics interested in knowing the customer preferences in developing countries like Ghana. The findings of the study should be valuable for practitioners as well as for the new entrants in a typical African market. This study would also be helpful for improvement of the criteria said and considered by customers while patronizing a bank. In addition, the findings should be of immense interest to banks since the strengths and weaknesses of the respective banks could be identified. This should help the banks to better position themselves and formulate effective strategies to gain competitive advantage. As Huu and Karr (2000) noted, "it is important to understand the preferences of the bank consumers and to design strategies to match their needs and the products/services of the banks". The modelling of consumer preferences by the AHP could have a crucial role in bank marketing in Ghana. By understanding that bank service quality is of greatest importance to customers, a bank can refocus its resources to lower costs and business risk while boosting market share and profitability. Knowing that service quality is of great value, a bank is able to differentiate from competition on the true underlying determinants of consumers' selection and gain a sustainable competitive advantage, being able to attract new customers and build effective long-term relationships with them.

\subsection{Limitations and Further Research}

One limitation of this study comes from the fact that the field research was conducted only in Accra, Ghana. Further, the specific characteristics of the Ghanaian financial services market, which cannot be considered as a mature market compared to those in industrialized markets, generate concern. Thus, one must guard against generalizations. Although this study highlights the issue of bank choice criteria, generating useful findings, future research in the area of bank marketing is needed. This study however used only subjective criteria based on focus group discussions and therefore other researchers can test the framework quantitatively to allow for generalizability. For future studies, we hope these limitations would encourage future studies on the topic. It is recommended that comparative study on selection criteria for banks can also be conducted in future

\section{References}

Almossawi, M. (2001). Bank selection criteria employed by college students in Bahrain: An empirical analysis. International Journal of Bank Marketing, 19(3), 115-125. http://dx.doi.org/10.1108/02652320110388540

Anderson, W.T., Cox, E.P., \& Fulcher, D.G. (1976). Bank selection decision and market segmentation. Journal of Marketing, 40, 40-5.

Beerli, A., Martin, J. D., \& Quintana, A. (2004). A model of customer loyalty in the retail banking market. European Journal of Marketing, 38(1/2), 253-275. http://dx.doi.org/10.1108/03090560410511221

Beckett, A., Hewer, P., \& Howcroft, B. (2000). An exposition of consumer behaviour in the financial services industry. International Journal of Bank Marketing, 18(1), 15-26. http://dx.doi.org/10.1108/02652320010315325

Blankson, C., Ming-Sung, J. C., \& Spears, N. (2007). Determinants of banks selection in USA, Taiwan and Ghana. International Journal of Bank Marketing, 25(7), 469-489. http://dx.doi.org/10.1108/02652320710832621

Boyd, W.L., Leonard, M., \& White, C. (1994). Customer preferences for financial services: an analysis. International Journal of Bank Marketing, 12(5), 9-15. http://dx.doi.org/10.1108/02652329410049562

Buerger, J. E., \& Ulrich, T. A. (1986). What's important to small business in selecting a financial institution. Journal of Commercial Bank Lending, 69, 3-9.

Cook, D. T. (2009). Knowing the child consumer: historical and conceptual insights on qualitative children's consumer research. Young Consumers, 10(4), 269-282. http://dx.doi.org/10.1108/17473610911007111

Cunningham, L.F., Young, C.E., Lee, M., \& Ulaga, W. (2006). Customer perceptions of service dimensions: cross-cultural analysis and perspective. International Marketing Review, 23(2), 192-210. http://dx.doi.org/10.1108/02651330610660083 
Dickinson, J.R., \& Wilby, C.P. (1997). Concept testing with and without product trial. Journal of Product Innovation Management, 14(2), 117-25. http://dx.doi.org/10.1016/S0737-6782(96)00097-5

Denton, L., \& Chan, A. K. K. (1991). Bank selection criteria of multiple bank users in Hong Kong. International Journal of Bank Marketing, 9(4), 23-34. http://dx.doi.org/10.1108/02652329110007129

Devlin, J.F. (2002). Customer knowledge and choice criteria in retail banking. Journal of Strategic Marketing, 10(4), 273-90. http://dx.doi.org/10.1080/0965254022000014541

Evans, R.H. (1979). Bank selection: it all depends on the situation. Journal of Bank Research, 12, 242-245.

Gerrard, P., \& Cunningham, J.B. (2001). Singapore undergraduates: How they choose which bank to patronize. International Journal of Bank Marketing, 19(3), 104-114. http://dx.doi.org/10.1108/02652320110388531

Gilbert, E. (1957). Advertising and Marketing to Young People. Printer's Ink Books, Pleasantville, NY.

Gupta, Y.P., \& Torkzadeh, G. (1988). Re-designing bank service: systems for effective marketing. Long Range Planning, 21, 38-43. http://dx.doi.org/10.1016/0024-6301(88)90157-4

Hinson, R., Dasah, J., \& Owusu-Frimpong, N. (2009). Undergraduate first time bank customers' perception of service quality in Ghana. International Business Economics, Working Paper Series, No. 49.

Hinson, R., Owusu-Frimpong, N., \& Dasah, J. (2009). Key motivations for bank patronage in Ghana. International Journal of Bank Marketing, 27(5), 381-399. http://dx.doi.org/10.1108/02652320910979898

Holstius, K., \& Kaynak, E. (1995). Retail banking in Nordic countries: the case of Finland. International Journal of Bank Marketing, 13, 10-20. http://dx.doi.org/10.1108/02652329510098873

Hon, K.Y., \& Tom, G. (1995). How the Chinese select their banks. Journal of Retail Banking, 14, 36-39.

Huu, P. T., \& Kar, Y. H. (2000). A study of bank selections in Singapore using the Analytical Hierarchy Proces. International Journal of Bank Marketing, 18(4), 170-180. http://dx.doi.org/10.1108/02652320010349058

Katircioglu, S.T, Tumer, M., \& Kılınç, C. (2011). Bank selection criteria in the banking industry: An empirical investigation from customers in Romanian cities. African Journal of Business Management, 5(14), 5551-5558. http://dx.doi.org/10.5897/AJBM11.408

Kaynak, E. (1986). How to measure your bank's personality: some insight from Canada. International Journal of Bank Marketing, 4(2), 54-68.

Kaynak, E., Kucukemiroglu, O., \& Odabasi, Y. (1991). Commercial bank selection in Turkey. International Journal of Bank Marketing, 9(4), 30-39.

Khazeh, K., \& Decker, W.H. (1993). How customers choose banks. Journal of Retail Banking, 14, 41-44.

Kotler, P. (2000). Marketing Management (The millennium ed.). Upper Saddle River, NJ. Prentice-Hall.

Laroche, M., Rosenblatt, J., \& Manning, T. (1986). Services used and factors considered important in selecting a bank: an investigation across diverse demographic segments. International Journal of Bank Marketing, 4(1), 35-55.

Lewis, B. R. (1982). Student accounts: A profitable segment? European Journal of Marketing, 16(3), 63-72

Mason, J.B., \& Mayer, M.L. (1974). Differences between high-and-low-income savings and checking account customers. The Magazine of Bank Administration, 65(3), 48-52.

Mishkin F.S. (2001). The Economics of Money, Banking and Financial Markets (6th ed.). Reading, MA: Addison-Wesley.

Mokhlis, S. (2009). Determinants of choice criteria in Malaysia's retail banking: Analysis of gender-based choice decisions. European Journal of Economics, Finance and Administrative Sciences, (16).

Mokhlis, S., Salleh, H. S., \& Mat, N.H.N. (2009). Commercial bank selection: comparison between single and multiple bank users in Malaysia. International Journal of Economics and Finance, 1(2), 263-273.

Morgan D.L. (1993). Successful Focus Groups: Advancing the State of the Art. California: Sage Publications Inc.

Pass, M. W. (2006). Western US college students: Banking preferences and marketplace performance. Journal of Financial Services Marketing, 11, 49-63. http://dx.doi.org/10.1057/palgrave.fsm.4760016

Razavi, S.M., Safari, H., Shafie, H., \& khoram, K. (2012). Relationships among Service Quality, Customer Satisfaction and Customer Perceived Value: Evidence from Iran's Software Industry. Journal of Management \& Strategy, 3(3), 29-37. http://dx.doi.org/10.5430/jms.v3n3p28 
Schlesinger, W. D., Unsal, F., \& Zaman, M. R. (1987). Attributes of sound banking as perceived by small business: Results of a survey. Journal of Small Business Management, 25, 47-53.

Schram, J. (1991). How student choose their banks. US Banker, 110, 75-78.

Spears, N., Lin, X., \& Mowen, J.C. (2001). Time orientation in the United States, China, and Mexico: measurement and insights for promotional strategy. Journal of International Consumer Marketing, 13(1), 57-74. http://dx.doi.org/10.1300/J046v13n01_05

Thwaites, D., \& Vere, L. (2010). Bank selection criteria: A student perspective. Journal of Marketing Management, (11), 133-149. http://dx.doi.org/10.1080/0267257X.1995.9964334

Thwaites, D., Brooksbank, R., \& Hanson, A. (1997). Bank selection criteria in New Zealand: A student perspective. New Zealand Journal of Business, $19(1$ \& 2), 95-107.

Weber, M. (1949). The Methodology of the Social Sciences. Free Press, New York, NY.

World Bank. (2012). Role of Services in Economic Development; Geneva, July 2012. Data source: World Bank, 2010.

Yin, R. K. (2003). Case Study Research: Design and Methods ( $3^{\text {rd }}$ ed.). Sage Publications, Thousand Oaks, CA.

Yoo, B., Donthu, N., \& Lee, S. (2000). An examination of selected marketing mix elements and brand equity. Journal of the Academy of Marketing Science, 28(2), 195-211.

Yue, H., \& Tom, G. (1995). How the Chinese Select their Banks. Journal of Retail Banking, 14(4).

Zineldin, M. (1996). Bank strategic positioning and some determinants of bank selection. International Journal of Bank Marketing, 14(6), 12-22. http://dx.doi.org/10.1108/02652329610130136 